\title{
Assembling Wormlike Micelles in Tubular Nanopores by Tuning Surfactant-Wall Interactions
}

Bhuvnesh Bharti ${ }^{1}$, Mengjun Xue ${ }^{1}$, Jens Meissner ${ }^{1}$, Viviana Cristiglio ${ }^{2}$ and Gerhard H Findenegg ${ }^{1, *}$

${ }^{1}$ Technische Universität Berlin, Institut für Chemie, Stranski Laboratorium, TC 7, Strasse des 17. Juni 124, D-10623 Berlin, Germany

${ }^{2}$ Institut Laue Langevin, Large Scale Structures group, 6, rue Jules Horowitz, BP 156 F-38042, Grenoble, France.

*corresponding author, e-mail address: findenegg@chem.tu-berlin.de 

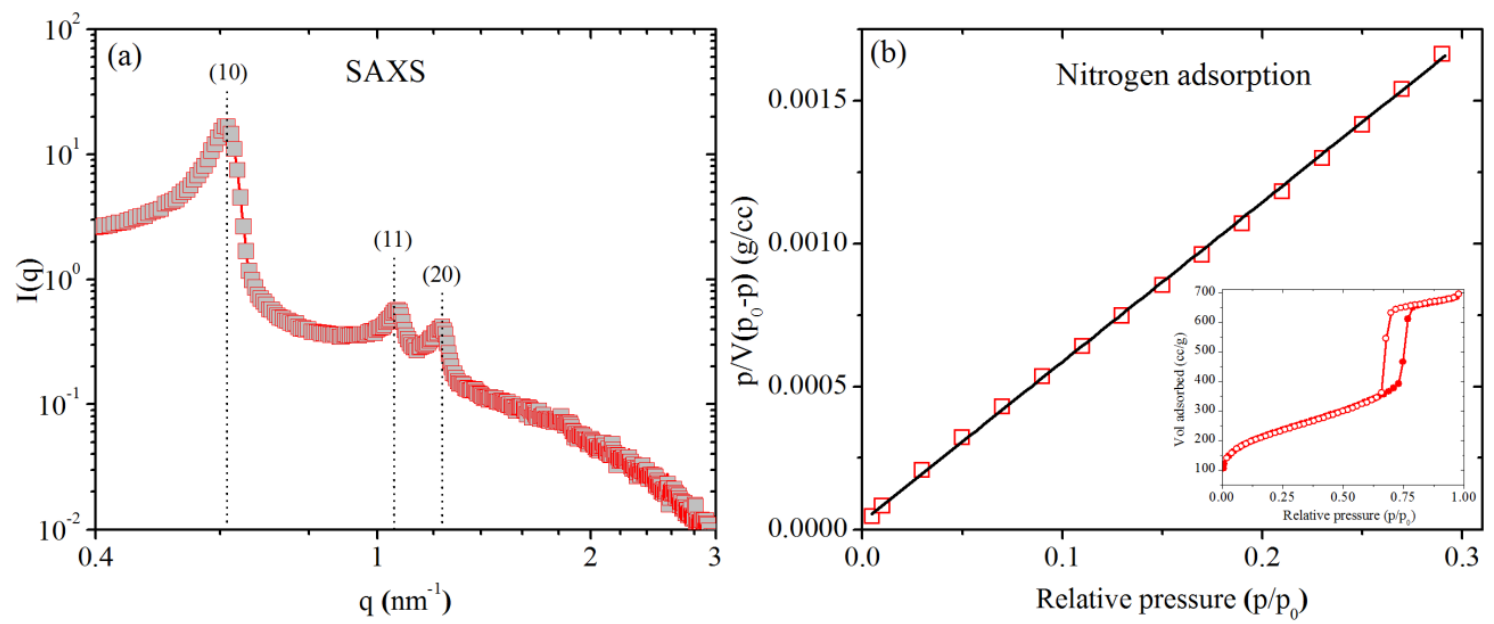

Figure S1 Characterization of synthesized silica SBA-15: (a) Small Angle X-ray Scattering (SAXS) profiles on double logarithmic scale. The vertical lines (dotted) mark the position of the three Bragg reflections (b) BET plot of Nitrogen adsorption isotherm (inset). The specific surface area of the material was found to be $773 \mathrm{~m}^{2} / \mathrm{g}$.

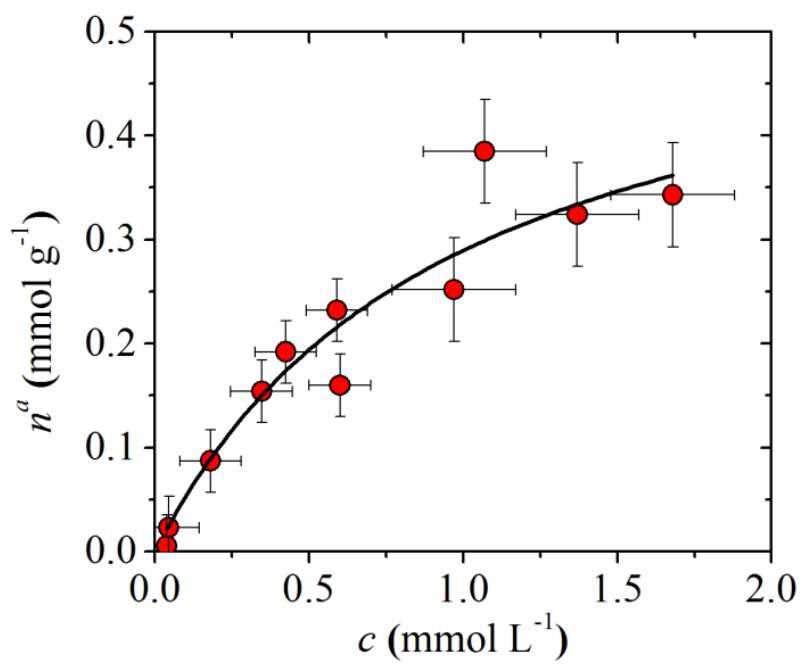

Figure S2 Lysine adsorption isotherm $\left(25^{\circ} \mathrm{C}\right)$ at SBA-15 silica. The points are the measured experimental data and the solid line is fit according to Langmuir model. 


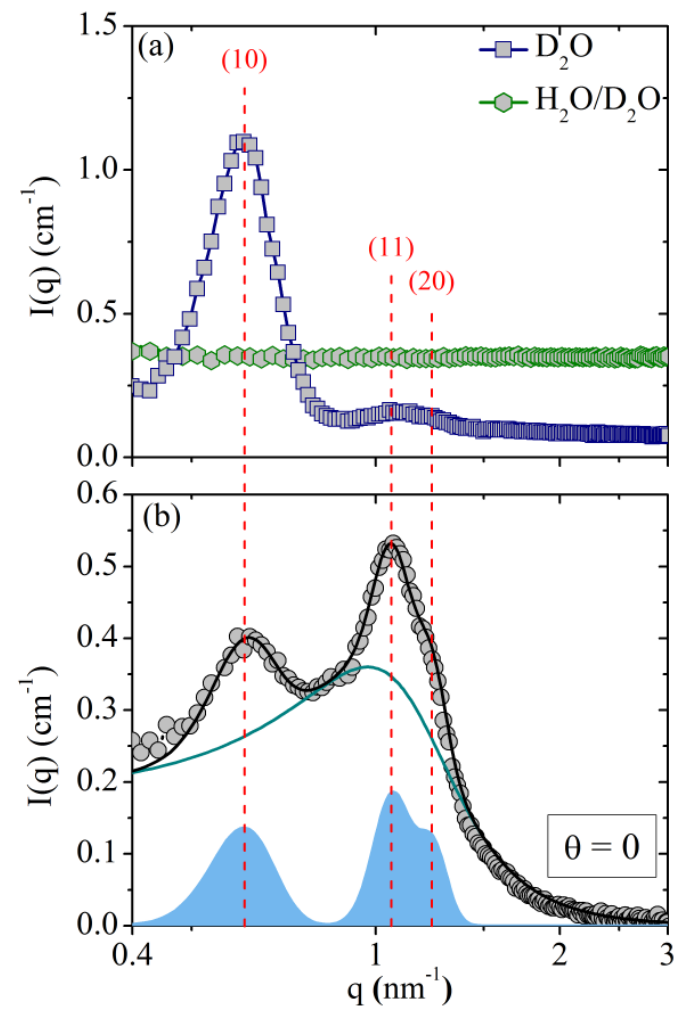

Figure S3 (a) SANS curves from SBA-15 immersed in pure $\mathrm{D}_{2} \mathrm{O}$ (blue squares) and in the contrastmatching $\mathrm{H}_{2} \mathrm{O} / \mathrm{D}_{2} \mathrm{O}$ mixture (green hexagons); the positions of the three leading Bragg reflections are indicated by dotted vertical lines. (b) Scattering profile from SBA-15 in $\mathrm{H}_{2} \mathrm{O} / \mathrm{D}_{2} \mathrm{O}$ with the surfactant $\mathrm{C}_{12} \mathrm{E}_{5}$ at relative filling $f=0.95$ in the absence of lysine $(\theta=0)$ : the black line represents a fit to the data points (circles), with the diffuse scattering contribution $I_{\text {diff }}(q)$ according Teubner-Strey model (green curve) and the Bragg scattering contribution $I_{\text {Bragg }}(q)$ according three independent Gaussians (see main text) indicated by the contour of the shaded areas. 